\title{
Shape Variation and Allometry in the Precloacal Vertebral Series of the Snake Daboia russelli (Viperidae)
}

\author{
Variación Morfológica y Alometría de las Vértebras \\ Precloacales en el Ofidio Daboia russelli (Viperidae)
}

Ioannis Sarris; Jesús Marugán-Lobón; Beatriz Chamero \& Ángela D. Buscalioni

SARRIS, I.; MARUGÁN-LOBÓN, J.; CHAMERO, B. \& BUSCALIONI, A. D. Shape variation and allometry in the precloacal vertebral series of the snake Daboia russelli (Viperidae). Int. J. Morphol., 30(4):1363-1368, 2012.

SUMMARY: Understanding the variation of the ophidian vertebral morphology is an essential tool in snake paleobiology, but so far this field remains hardly investigated. A major problematic is the still scarce knowledge about the basis of homogeneity of intracolumnar shape variation along the vertebrae of the precloacal region in these animals. For instance, this variation can be overwhelmingly low in cases such as in vipers, for which it seems almost impossible to describe a concrete regionalization of the precloacal region without ambiguity. This study has applied geometric morphometrics to analyze if the shape variation of the vertebrae of the precloacal vertebrae of an adult specimen of Daboia russelli allows differentiating any sort of parcellation within the column of this organism. We have also explored if size is associated with the organization of vertebral shape along the axial skeleton. The multivariate analyses showed that the main pattern of vertebral shape variation in D. russelli concerns the neural spine and the hypapophysis, whereas the shape of the vertebral centrum appears to be nearly invariant along the series. Our analysis also showed that the precloacal region can be sudivided into two portions that merge in a transitional boundary of largest vertebrae in the middle of the column. From this middle region towards the distal ends of the column vertebrae become smaller changing their shapes in two antithetical ways.

KEY WORDS: Intracolumnar variation; Russells viper; Axial skeleton; Serial homology; Vertebral morphology.

\section{INTRODUCTION}

The features that best characterize snake evolution are the total reduction of limbs and an extreme body elongation, often encompassed by hundreds of vertebrae (Gans, 1975; Romer, 1956). Regardless of the mechanisms involved in this phenomenon, the homogenization of vertebral shapes blurs the boundaries between axial areas of the adult snake, making it very difficult to assign an isolated vertebra to a putative position in the column (Romer; Hoffstetter \& Gasc, 1969). In fact, the recognition of regions in the vertebral column causes disagreement among ophidiologists (Cohn \& Tickle, 1999; Caldwell, 2000; Tsuihiji et al., 2006; Woltering et al., 2009).

The vertebrae are elements of a seriated structure, and their variation is continuous along the precloacal region of the column. Thus, their variability can be accurately assessed applying morphometrics methods (e.g. Thireau, 1967; Szyndlar, 1984), and in particular with geometric morphometrics (GMM) (Bruner \& Bartolino, 2008). Using this tool, Polly \& Head (2004) attempted to predict verte- bral shape relative to position along the vertebral column in snakes, concluding that the largest probability of success was concentrated at the distal parts of the column, stressing that shape variability is larger at the middle of the trunk. However, such an approach required an arbitrary subdivision of the precloacal region, neglecting the biological fact that vertebral size and shape may vary orderly and continuously along the column (Sarris \& Chamero, 2009). If this order is case-specific, it is necessary to first evaluate its pattern within a single individual, as a means to single out the sources of vertebral variability.

This study assesses the pattern of intra-individual changes of the precloacal vertebral series of an adult specimen of Daboia russelli (Viperidae) using GMM. We provide a detailed mapping of the pattern of size and shape variation and the association of the vertebral series of Daboia following this analytical protocol: 1) assess the shape variability of vertebrae using Principal Components Analysis, 2) evaluate the integration among vertebral 
elements, testing the statistical covariation between neural archs and centra with Two-block Partial Least Squares, and 3) estimate the relationship between vertebral size and shape variability using multivariate Regression Analysis. We demonstrate how the morphological organization of the vertebral series of a snake depends on an intricate coupling between vertebral shape and size variation along the column.

\section{MATERIAL AND METHOD}

We used a total sample of $n=98$ vertebrae out of the 156 vertebrae that encompass the complete precloacal region. The studied Daboia russelli specimen (MNCN16538) is housed at the Museo Nacional de Ciencias Naturales of Madrid. Although based on a single adult specimen, this sample size fulfills statistical requirements

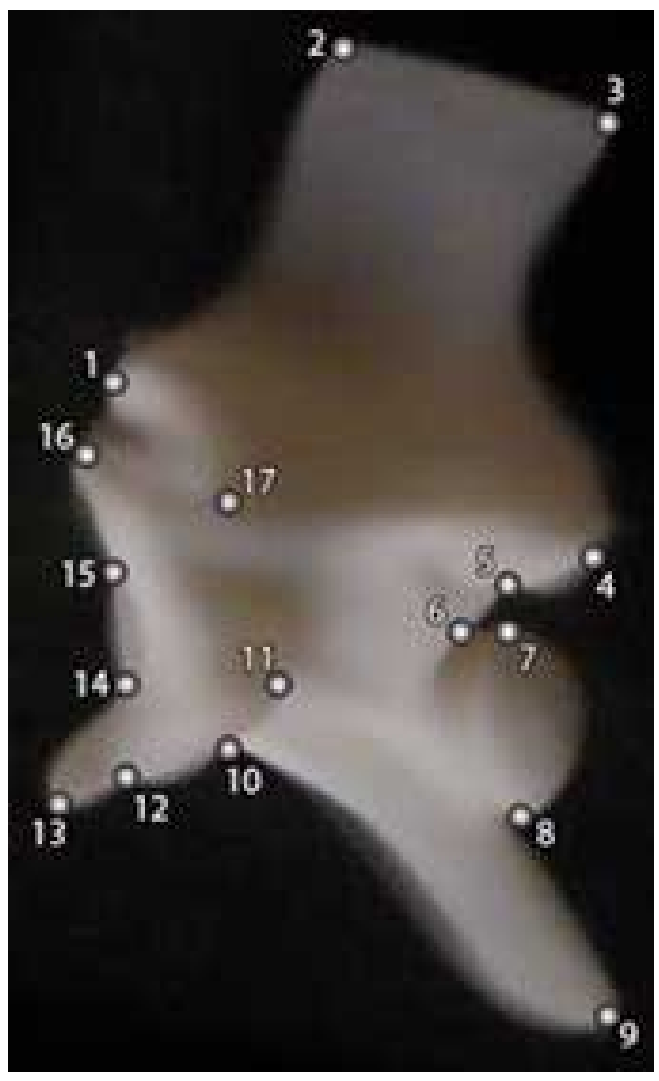

Fig. 1. Left lateral view of the consensus image of the precloacal vertebrae of $D$. russelli with the landmarks that have been analyzed. and is fully representative of a snake's columnar pattern of variation. Moreover, the proposed statistical protocol could be generalized to address the morphological organization of the vertebral column in any snake species.

Each single vertebra was photographed in left lateral view using a digital camera, since this view contains the largest amount of morphological information (Johnson, 1955). The coordinates of the $\mathrm{p}=17$ landmarks (Fig. 1) were digitized on each image using TPSdig2 (version 2.15; Rohlf, 2010). The nomenclature used for the anatomical description follows Auffenberg (1963), Szyndlar and Rage (1984). The configuration of landmarks outlines the major constitutive parts of a vertebra, namely, the neural arch (neural spine included; landmarks 1 through 4), the centrum (landmarks 5-8 and 10-17) and the hypapophyses (landmarks 8-10).

In order to remove all the information unrelated to shape, the configurations were superimposed using Generalized Full Procrustes Analysis (Zelditch et al., 2004). The purpose of this geometric approach is to match two or more configurations of points in a Euclidean space using a one-to-one mapping among the sets of points (Cox \& Cox, 2001). Full Procrustes superimpositions rely on translation, scaling and rotation to minimize differences between the configurations using the Least Squares criterion (Rohlf \& Slice, 1990; Gower \& Dijksterhuis, 2004; Zelditch et al.).

The intracolumnar variation of the vertebrae was analyzed with Principal Components Analysis (PCA). This technique determines the principal dimensions that explain the highest variation as linear combinations of the original variables (Hammer \& Harper, 2006). These variables were the shape residuals of the Full-Procrustes superimposition. The covariance matrix was generated from the Procrustes coordinates matrix, and the eigenvectors were calculated with their corresponding eigenvalues.

The morphological co-variation between vertebral parts, namely the neural arch and centrum, was analyzed according to a Two-block Partial Least-Squares analysis criterion (2B-PLS), searching for the combination of latent variables that account for the highest co-variation between the two block data (Rohlf \& Corti, 2000). The RV coefficient (Klingenberg, 2009) was used to estimate the statistical significance (using 10,000 interactions) of covariation between blocks, whereby integration is interpreted between 0 and 1 (the latter meaning total integration).

The sizes of each vertebra were computed as the centroid size (CS) of each landmark configuration (the square root of the sum of all the square distances between the landmarks; Bookstein, 1991). The relationship between CS and vertebral shape variability was studied with a multivariate regression using size as a predictor (i.e. independent) variable. This analysis yields a vector that has the highest correlation with size (Drake \& Klingenberg, 2008). All the analyses and the Procrustes procedures were performed using MorphoJ (version 1.04a; Klingenberg, 2008). 


\section{RESULTS}

Shape analysis. The first principal component (PC1) accounts for most of the morphological variance among vertebrae (79.38\%), while the second (PC2) only captures $7.6 \%$ (Fig. 2A), therefore PCs other than the first two are negligible. The scatter plot between the first two principal components displays an ordered sequence of the vertebrae in a curved arrangement, in which the numeric position of each vertebra in the vertebral column nearly represents the real spatial location in the array. Thus the PC1 shows the seriated order of the column from negative (anterior part) to positive (posterior part). PC1 accounts for the antero-posterior enlargement of the vertebrae and a relative height decrease, also encompassing a more pronounced dorso-ventral reduction of the neural spine and the hypapophysis. At the same time the prezygapophyses are relatively more elevated and slightly longer, and the parapophyseal processes appear more anteriorly than ventrally directed.

The degree of covariation among the vertebral parts is relatively high $(\mathrm{RV}=0.71, \mathrm{p}<0.0001)$, denoting a relatively high level of integration between neural arches and centra. The first PLS dimension (98.82\% of the total explained covariation; Fig. 2B) reveals that the centra are likely to be less variable in shape than the neural arches. The centrum morphology is constant throughout the anterior area. In addition, neural arch changes are continuous bearing a predictable signature of position.
A
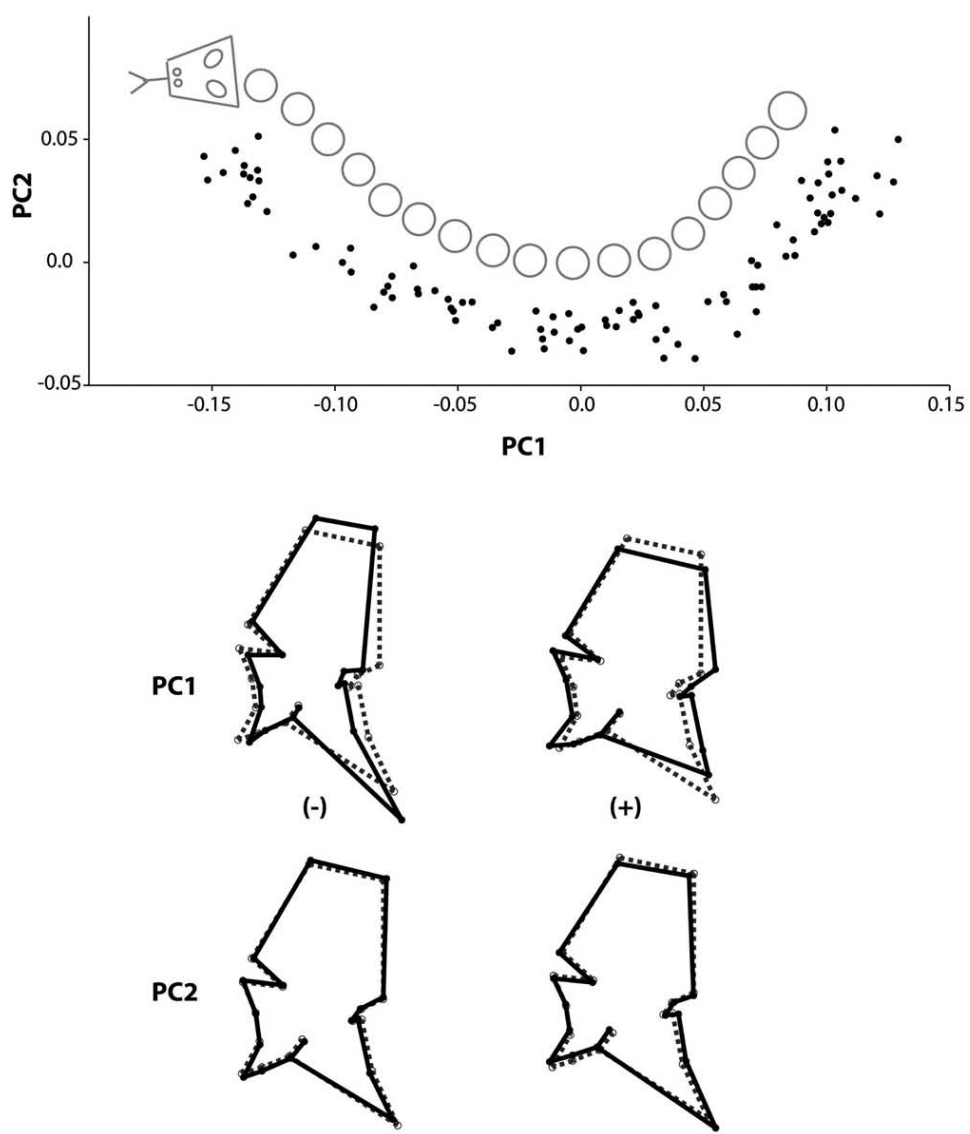

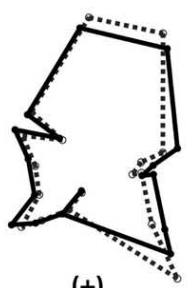

$(+)$

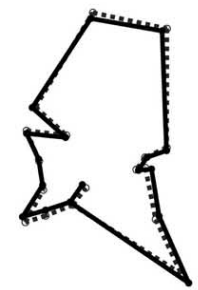

B
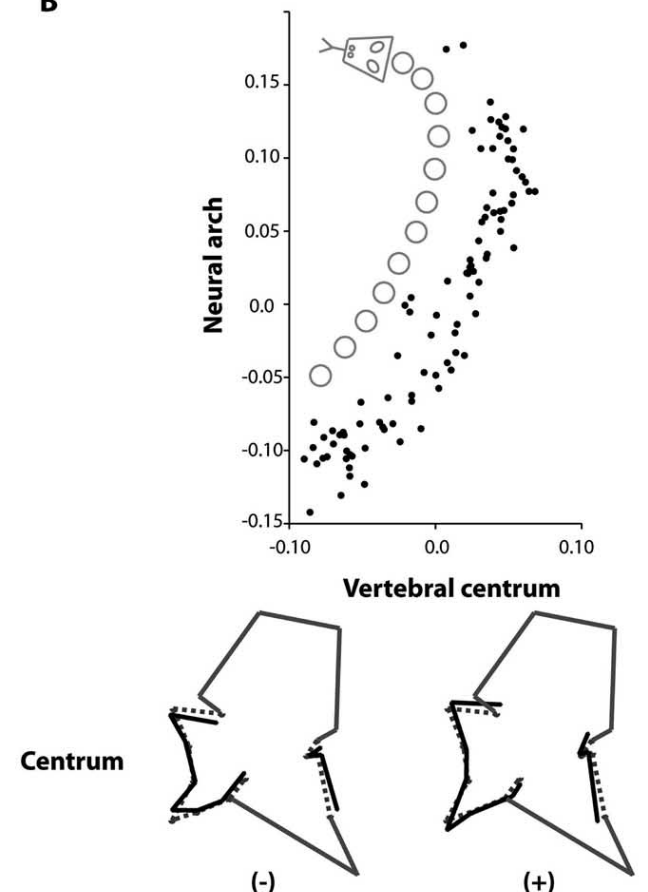

$(+)$

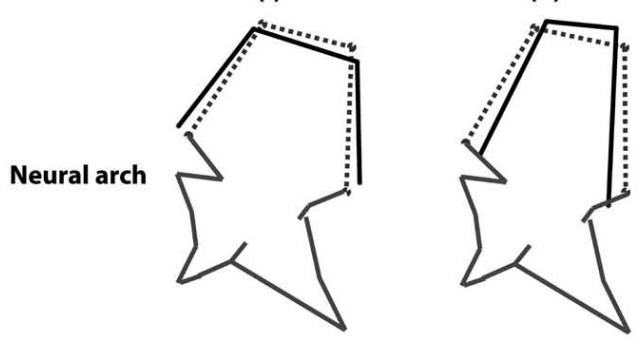

Fig. 2. Vertebral shape analysis of the precloacal region of Daboia russelli. The shape changes of the configurations along the axes are shown using wireframes and represent the extreme deformation (solid black line) compared with the medium shape (dotted grey line). The order of the vertebrae is expressed by the drawn snake. (a) Plot of PC1 and PC2, where PC1 explains 79.38\% and PC2 explains 7.6\% of the total variance. (b) Plot of the first 2B-PLS dimension that explains $98.82 \%$ of the total covariation $(\mathrm{RV}$ coefficient $=0.71$ and $\mathrm{p}<0.0001)$. The part of the vertebrae that is excluded from each analysis is drawn with grey solid line. 
Multivariate regressions (size and shape). As in the PCA, the shape vector correlated with size shows a correspondence between the U-shaped scatter plot distribution and the numerical positions of the vertebrae in the column (Fig. 3A). The distribution of vertebral shape variation in figure $3 \mathrm{~A}$ owes this curved scatter to the fact that the size is also bellshaped (Fig. 3B). However, the U-scatter is asymmetrical,

A

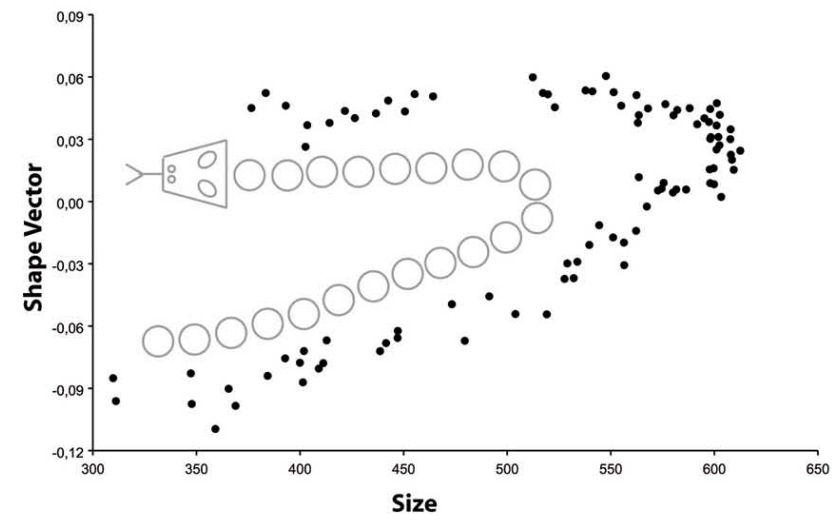

denoting a different correlation between size and shape: whereas the anterior area ( 3 to 50th) is isometric, the posterior area ( $\sim 70$ to 148 th) is allometric and positively correlated with size. It is noteworthy that in the middle area ( $\sim 50$ to 70$)$ the vertebra shapes are uncorrelated with size. Thus, the latter area delimits a number of vertebrae without size change but shape variance.

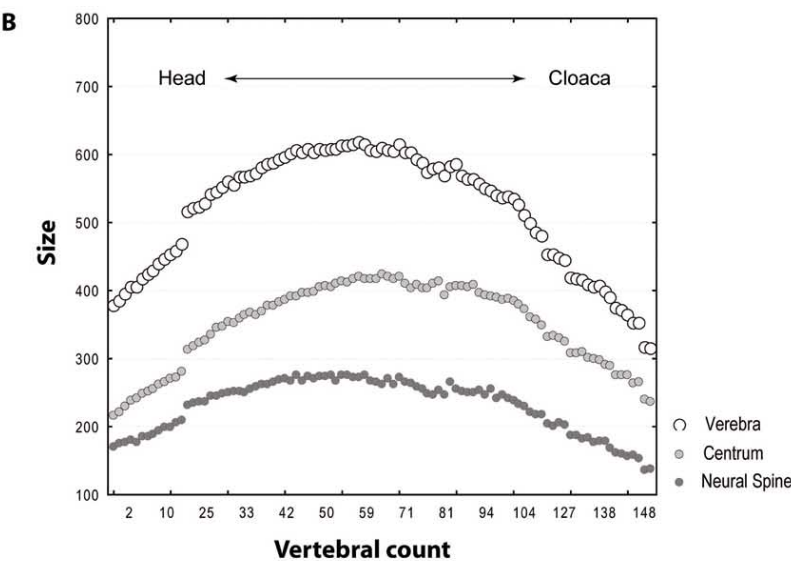

Fig. 3. Size and shape of the precloacal vertebral morphology of Russell's viper. (a) Plot of the Regression Analysis that shows the relationship between the vertebral size (centroid size) and the shape vector that is more correlated with it. The order of the vertebrae is expressed by the drawn snake. (b) Plot that shows the variation of the vertebral, centrum and neural arch size along the column.

\section{DISCUSSION}

The study of snake vertebral morphology with GMM is a field that remains poorly explored. Our primary interest in assessing the vertebral shape variation of a single individual was to address the morphological organization of the snake's precloacal region attending to its main biological properties: serial structures and continuous variation. The serial configuration of the axial skeleton provides the opportunity of estimating the variation in shape of each consecutive vertebra, and to test the association of that variation and changes in size along the column. This relationship, known as allometry, has a singular connotation in the context of a single individual, which we disclose below.

In the arrangement of the snake's axial skeleton, all vertebral parts follow a gradual and monotonic shape variation along the column, making the ends the most distinct in shape. This would make the chances of identifying an area along the column from an isolated vertebra easier if the vertebra belongs to distal ends. This explains why in a likelihood test, the probability to match the shape of distal vertebrae to their corresponding location along the column was found to be higher than that to match the shape of middle ones (Polly \& Head). Yet, the centrum contributes less to vertebral distinctness than the neural spine and the hypapophysis (Fig. 2A, B).

Geometric morphometrics-a method which treats size and shape independently, allowing to test their multidimensional association (Rohlf \& Marcus, 1993; Adams et al., 2004)—indicates that the gradual shape variation of vertebrae along the column is intricately connected with the serial size variation along the column. In fact, there is a differential association between vertebral shape and size along the column, such that it makes it impossible to predict any vertebral shape from size. Namely, for a same range of size there are always at least two different vertebral shapes. Notice, however, that if one considers only the posterior portion of the precloacal region, there appears to be a subtle linear predictability of vertebral shape by size.

Our analysis on the precloacal region in Daboia russelli prompts further questions regarding development, growth and function. For instance, to what extent is the homogenization of Hox gene expression (Cohn \& Tickle; Woltering et al.), the mechanisms underlying the observed pattern of monotonic, gradual and continuous vertebral shape 
changes in Daboia russelli. In the same vein, to what extent would the available morphogenetic models (i.e., biochemical oscillators and segmentation clocks of Dubrulle \& Purquié, 2004; Dequéant \& Purquié, 2008; Gómez et al., 2008) match the complex assembly (decoupling) between shape and size in the arrangement of the snake skeleton? And finally, it would be worth testing whether the intricate connectedness of size and shape of the vertebrae along the body axis of a snake has an impact on its biomechanics and life style.

\section{ACKNOWLEDGMENTS}

We would like to thank J. E. González Fernández (Museo Nacional de Ciencias Naturales, Madrid) for loaning the snake skeleton. Funds provided by the project CGL200911838 BTE and a FPU grant (AP2007-00904; MICINN) to I. Sarris.

SARRIS, I.; MARUGÁN-LOBÓN, J.; CHAMERO, B. \& BUSCALIONI, A. D. Variación morfológica y alometría de las vértebras precloacales en el ofidio Daboia russelli (Viperidae). Int. J. Morphol., 30(4):1363-1368, 2012.

RESUMEN: Entender la variación en la morfología vertebral de los ofidios es crucial para la paleobiología del grupo pero, hasta ahora, este campo está poco investigado. Uno de los principales problemas es el escaso conocimiento sobre las bases de la homogeneidad en la variación de la forma a lo largo de la región precloacal en estos animales. Por ejemplo, en el caso de las víboras, dicha variación puede ser muy pequeña lo cual hace casi imposible la descripción de una regionalización precisa sin ambigüedad. En este estudio se ha aplicado morfometría geométrica para analizar si la variación de la forma vertebral de un individuo adulto de la especie Daboia russelli permite subdividir la región precloacal. Además, hemos explorado si el tamaño está asociado con la organización vertebral a lo largo del esqueleto axial. Los análisis multivariantes han demostrado que el patrón principal de la variación de la forma vertebral está determinado por la espina neural y la hipapofisis, mientras que el centro vertebral varía poco a lo largo de la serie. Nuestro análisis ha mostrado que la región precloacal puede ser dividida en dos series cuya separación está marcada por las vértebras más grandes, posicionadas aproximadamente en la mitad de la columna. Tomando como referencia la mitad de la columna, hacia los extremos distales, las vértebras tienden a ser más pequeñas cambiando su forma de modo antitético.

PALABRAS CLAVE: Variación intracolumnar; Víbora de Russell; Esqueleto axial; Homología seriada; Morfología vertebral.

\section{REFERENCES}

Adams, D. C.; Rohlf, F. J. \& Slice, D. E. Geometric morphometrics: ten years of progress following the "revolution". It. J. Zool., $71: 5-16,2004$.

Auffenberg, W. The fossil snakes of Florida. Tulane Stud. Zool., 10:131-216, 1963.

Bookstein, F. L. Morphometric tools for landmark data: Geometry and Biology. Cambridge, Cambridge University Press, 1991.

Bruner, E. \& Bartolino, V. Morphological variation in the seahorse vertebral system. Int. J. Morphol., 26(2):247-62, 2008.

Caldwell, M. W. On the aquatic squamate Dolichosaurus longicollis Owen, 1850 (Cenomanian, Upper Cretaceous), and the evolution of elongate necks in squamates. J. Vert. Paleontol., 20:720-35, 2000.

Cohn, M. J. \& Tickle, C. Developmental basis of limblessness and axial patterning in snakes. Nature, 399(6735):474-9, 1999.

Cox, T. F. \& Cox, M. A. A. Multidimensional Scaling. $2^{\text {nd }}$ ed. Florida, Chapman and Hall, 2001.

Drake, A. G. \& Klingenberg, C. P. The pace of morphological change: historical transformation of skull shape in St Bernard dogs. Proc. Biol. Sci., 275(1630):71-6, 2008.

Dequéant, M. L. \& Pourquié, O. Segmental patterning of the vertebrate embryonic axis. Nat. Rev. Genet., 9(5):370-82, 2008.

Dubrulle, J. \& Pourquié, O. fgf8 mRNA decay establishes a gradient that couples axial elongation to patterning in the vertebrate embryo. Nature, 427(6973):419-22, 2004.

Gans, C. Tetrapod limblessness: evolution and functional corollaries. Am. Zool., 15:455-67, 1975.

Gómez, C.; Ozbudak, E. M.; Wunderlich, J.; Baumann, D.; Lewis, J. \& Pourquié, O. Control of segment number in vertebrate embryos. Nature, 454(7202):335-9, 2008.

Gower, J. C. \& Dijksterhuis, G. B. Procrustes Problems. Oxford, Oxford University Press, 2004.

Hammer, O. \& Harper, D. Paleontological Data Analysis. Oxford, Wiley Blackwell, 2006.

Hoffstetter, R. \& Gasc, J. P. Vertebrae and ribs of modern 
reptiles. In: Gans, C. \& Bellairs, A. A. (Eds.). Biology of the Reptilia. Vol.1 (Morphology). London, Academic Press, 1969. pp.201-310.

Johnson, R. G. The adaptive and phylogenetic significance of vertebral form in snakes. Evolution, 9:367-88, 1955.

Klingenberg, C. P. Morphometric integration and modularity in configurations of landmarks: tools for evaluating a priori hypotheses. Evol. Dev., 11(4):405-21, 2009.

Klingenberg, C. P. MorphoJ. Faculty of Life Sciences, University of Manchester, UK, 2008. Available in: http:/ /www.flywings.org.uk/MorphoJ_page.htm

Polly, P. D. \& Head, J. J. Maximum-likelihood identification of fossils: taxonomic identification of Quaternary marmots (Rodentia, Mammalia) and identification of vertebral position in the pipesnake Cylindrophis (Serpentes, Reptilia). In: Elewa, A. M. T. (Ed.). Morphometrics: Applications in Biology and Paleontology. Heidelberg, Springer Verlag, 2004. pp.117221.

Rage, J. C. Serpentes. Part 11. In: Wellnhofer, P. (Ed.). Handbuch der Paläeoherpetologie. Stuttgart, Gustav Fischer, 1984.

Rohlf, F. J. TPSdig, Version 2.15. Ecology and Evolution. SUNY at Stony Brooks, USA, 2010. Available in: http:// life.bio.sunysb.edu/morph/soft-dataacq.html

Rohlf, F. J. \& Corti, M. Use of Two-Block Partial LeastSquares to study covariation in shape. Syst. Biol., 49(4):740-53, 2000.

Rohlf, F. J. \& Marcus, L. F. A revolution in morphometrics. Trends Ecol. Evol., 8(4):129-32, 1993.

Rohlf, J. F. \& Slice, D. Extensions of the Procrustes method for the optimal superimposition of landmarks. Syst. Biol., 39(1):40-59, 1990.

Romer, A. S. Osteology of the reptiles. Chicago, University of Chicago Press, 1956.

Sarris, I. \& Chamero, B. Serial homology and the horseshoe effect. I Iberian Symposium on Geometric Morphometrics. Sabadell, Spain, Paleontologia i Evolució, 2009. pp.111-2.

Szyndlar, Z. Fossil snakes from Poland. Acta Zool. Cracov., 28(1):1-156, 1984.
Thireau, M. Contribution a l'étude de la morphologie caudale de l'anatomie vertébrale et costale des genres Atheris, Atractaspis et Causus (vipéridés de l'ouest africain). Bull. Mus. Hist. Nat., 39:454-69, 1967.

Tsuihiji, T.; Kearney, M. \& Rieppel, O. First report of a pectoral girdle muscle in snakes, with comments on the snake cervico-dorsal boundary. Copeia, 2006(2):206-15, 2006.

Woltering, J. M.; Vonk, F. J.; Müller, H.; Bardine, N.; Tuduce, I. L.; de Bakker, M. A. G.; Knöchel, W.; Sirbu, I. O., Durston, A. J. \& Richardson, M. K. Axial patterning in snakes and caecilians: evidence for an alternative interpretation of the Hox code. Dev. Biol., 332(1):82-9, 2009.

Zelditch, M. L.; Swiderski, D. L.; Sheets, H. D. \& Fink, W. L. Geometric Morphometrics for Biologists: a primer. New York, Elsevier, 2004.

Correspondence to:

loannis Sarris

Unidad de Paleontología

Departamento de Biología

Universidad Autónoma de Madrid

28049, Cantoblanco

Madrid

SPAIN

Email: ioannis.sarris@uam.es

Received: 03-02-2012

Accepted: 14-05-2012 